\title{
Revenue Sharing in a Sports League with an Open Market in Playing Talent
}

\author{
Stephen Dobson'1, John Goddard 2 \\ ${ }^{1}$ University of Hull, Hull, UK \\ ${ }^{2}$ Bangor University, Bangor, UK \\ Email: s.m.dobson@hull.ac.uk, j.goddard@bangor.ac.uk
}

Received 4 April 2014; revised 4 May 2014; accepted 24 May 2014

Copyright (C) 2014 by authors and Scientific Research Publishing Inc.

This work is licensed under the Creative Commons Attribution International License (CC BY).

http://creativecommons.org/licenses/by/4.0/

c) (i) Open Access

\begin{abstract}
In this paper we develop an economic model of a professional sports league, in which the teams acquire playing talent in an external market. There have been several earlier formulations of this open model and all rely upon an inappropriately specified revenue function. Team revenues should depend upon the absolute quality of the teams, as well as their relative quality measured by win-percent. An inference that has been cited widely in this literature is that revenue sharing increases competitive inequality. We show that this analysis is flawed. If the revenue function is specified appropriately, gate revenue sharing always reduces competitive inequality.
\end{abstract}

\section{Keywords}

Professional Team Sports, Revenue Sharing, Competitive Inequality

\section{Introduction}

This paper presents new results for an economic model of a professional sports league, in which the teams hire playing talent from an external market at a cost per unit of talent that is determined exogenously. In several previous studies, the teams' revenues are assumed to depend on the relative quantities of talent hired but not on the absolute quantities of talent. The Nash equilibrium differs from the joint profit maximizing equilibrium, and exhibits a higher degree of competitive balance. Consequently, the introduction of a gate revenue sharing arrangement tends to increase competitive inequality. This inference might seem somewhat counterintuitive.

In this paper, we argue that several previous formulations of this "open" model are based on an inappropriately specified revenue function. This paper demonstrates that revenue sharing always reduces competitive inequality if the teams' revenues depend not only on the relative quantities of talent, represented by win-percent, but also on the quantities of talent in absolute terms. The rest of the paper is organized as follows. Section 2 
examines the effect of revenue sharing on competitive inequality when revenues depend on win-percent only. Section 3 examines the effect of revenue sharing on competitive inequality when revenues depend on both win-percent and the absolute quantities of talent. Section 4 summarizes and concludes.

\section{Revenue Sharing When Revenue Depends on Relative Talent}

In this section, we review the proposition that revenue sharing increases competitive inequality in the open model with a competitive external market in playing talent. In the sports economics literature, it is common practice to present solutions for the special case of a two-team league. Most of the key insights obtained from the two-team model remain applicable, in an appropriately modified form, in the more realistic but less tractable case of the n-team league with $n>2$. The notation is as follows:

$t_{i}=$ quantity of talent hired by team $i(i=1,2)$.

$T=t_{1}+t_{2}=$ total quantity of talent hired by teams 1 and 2 .

$w_{i}=t_{i} / T=$ proportion of matches won by team $i$, referred to below as win-percent.

$m_{i}=$ market size parameter for team $i$.

$R_{i}=$ revenue generated by team $i$.

$c=$ marginal cost per unit of talent hired, assumed to be determined exogenously.

Revenue functions that depend upon relative team quality only may be specified $R_{1}=\sigma\left(w_{1}-\phi w_{1}^{2}\right)$ and $R_{2}=w_{2}-\phi w_{2}^{2}$. In this formulation, the market size measures are standardized such that $m_{2}=1$, and $\sigma=m_{1} / m_{2}$. The algebra is simplified in the special case $\phi=0.5$, but the properties of the model are qualitatively identical for the general case $\phi \leq 0.5$ as shown in Vrooman [1]. We present results for the special case only.

The early literature and some recent studies, based on "Walrasian conjectures", assumes a fixed supply of playing talent, such that any increase in $t_{1}$ is matched by an offsetting reduction in $t_{2}$, or $\mathrm{d} t_{1} / \mathrm{d} t_{2}=-1$ (see Fort and Quirk [2]; Dietl, Lang and Rathke [3]). Several other recent studies adopt “Nash conjectures”, by assuming a perfectly elastic supply of talent, such that $\mathrm{d} t_{1} / \mathrm{d} t_{2}=0$ (see Szymanski and Késenne [4]; Késenne [5]; Vrooman). The implications of a talent supply function that lies between these two extremes are explored by Cyrenne [6] and Fort and Winfree [7]. Under Nash conjectures, the partial derivatives of $R_{1}$ and $R_{2}$ are

$$
\begin{array}{ll}
\frac{\partial R_{1}}{\partial t_{1}}=\frac{\partial R_{1}}{\partial w_{1}} \frac{\partial w_{1}}{\partial t_{1}}=\sigma\left(1-w_{1}\right) w_{2} / T & \frac{\partial R_{2}}{\partial t_{1}}=\frac{\partial R_{2}}{\partial w_{2}} \frac{\partial w_{2}}{\partial t_{1}}=-\left(1-w_{2}\right) w_{2} / T \\
\frac{\partial R_{1}}{\partial t_{2}}=\frac{\partial R_{1}}{\partial w_{1}} \frac{\partial w_{1}}{\partial t_{2}}=-\sigma\left(1-w_{1}\right) w_{1} / T & \frac{\partial R_{2}}{\partial t_{2}}=\frac{\partial R_{2}}{\partial w_{2}} \frac{\partial w_{2}}{\partial t_{2}}=\left(1-w_{2}\right) w_{1} / T
\end{array}
$$

We assume revenues are shared according to a pool-sharing arrangement, such that each club contributes a proportion $\alpha$ of its gross revenues to a pool that is distributed equally between the teams. The first-order conditions for profit maximization, based on the net revenue functions $\bar{R}_{i}=\alpha R_{i}+\{(1-\alpha) / 2\}\left(R_{i}+R_{j}\right)$, and assuming a perfectly elastic supply of talent, are

$$
M R_{1}=\alpha \frac{\partial R_{1}}{\partial t_{1}}+\frac{(1-\alpha)}{2}\left\{\frac{\partial R_{1}}{\partial t_{1}}+\frac{\partial R_{2}}{\partial t_{1}}\right\}=c \quad M R_{2}=\alpha \frac{\partial R_{2}}{\partial t_{2}}+\frac{(1-\alpha)}{2}\left\{\frac{\partial R_{1}}{\partial t_{2}}+\frac{\partial R_{2}}{\partial t_{2}}\right\}=c
$$

where $M R_{\mathrm{i}}$ denotes marginal (net) revenue. A measure of competitive inequality is obtained using $M R_{1}-M R_{2}=$ 0 .

$$
M R_{1}-M R_{2}=0 \Rightarrow \frac{w_{1}^{2}}{w_{2}^{2}}=\sigma+(\sigma-1)\left(\frac{1-\alpha}{1+\alpha}\right) \frac{w_{1}}{w_{2}}
$$

For $\alpha=1$ (no revenue sharing), $w_{1} / w_{2}=\sqrt{\sigma}$. For $\alpha=0$ (equal revenue sharing), $w_{1} / w_{2}=\sigma . \sigma>1$ ensures competitive inequality is greater with $\alpha=0$ than it is with $\alpha=1$. Competitive inequality increases as $\alpha$ decreases within the range $0<\alpha<1$.

If revenues depend upon relative team quality only, however, the equal revenue sharing solution $(\alpha=0)$ is degenerate. By reducing their absolute quantities of talent hired towards zero, but doing so in a manner that is consistent with the relativities required to satisfy the first-order conditions, the teams always increase their joint profits. The solutions for the joint profit maximizing quantities of talent $\left\{t_{1}, t_{2}\right\}$ are obtained by summing the two first-order conditions: 


$$
M R_{1}+M R_{2}=2 c \Rightarrow w_{1}^{2}-(\sigma+1) w_{1} w_{2}+\sigma w_{2}^{2}=4 c T^{2}
$$

Substituting $w_{1} / w_{2}=\sigma$ into [2] makes the left-hand-side zero. Accordingly, $T=0$ and $\left\{t_{1}, t_{2}\right\}=\{0,0\}$. The degenerate nature of the joint profit maximization solution, and the inference that revenue sharing increases competitive inequality, derive from a counterfactual corollary of the assumption that revenue depends upon win-percent only. This assumption implies that provided the relative quantities of talent hired by the two teams are maintained, revenue is unaffected when the absolute quantities of talent are reduced towards zero.

\section{Revenue Sharing When Revenue Depends on Relative and Absolute Talent}

In this section, we propose a multiplicative revenue function consisting of two components: a term that is quadratic in the total quantity of talent employed by both competing teams; and a term that is quadratic in win-percent. In common with Cyrenne and Fees and Stahler [8], we posit a direct relationship between the absolute quantities of talent and revenue. In contrast, however, the multiplicative form of our model allows for the interaction between absolute and relative team quality in a straightforward manner. Falconieri, Palomino and Sakovics [9], who focus on the sharing of television revenue as opposed to gate revenue, consider a further variant in which revenue depends on the total absolute quantity of talent and the level of competitive inequality, but not on the quantity of home team relative to away team talent.

In our case, the proposed revenue functions are $R_{1}=\sigma\left(T-\gamma T^{2}\right)\left(w_{1}-\phi w_{1}^{2}\right)$ and $R_{2}=\left(T-\gamma T^{2}\right)\left(w_{2}-\phi w_{2}^{2}\right)$. The restriction $\phi \leq 0.5$ ensures $R_{i}$ is increasing in $w_{i}$ over the range of feasible values $0 \leq w_{i} \leq 1$. As before, we consider the special case $\phi=0.5$; the results are qualitatively identical in the general case. The partial derivatives of $R_{1}$ and $R_{2}$ are

$$
\begin{aligned}
& \frac{\partial R_{1}}{\partial t_{1}}=\sigma\left[(1-2 \gamma T)\left(w_{1}-0.5 \phi w_{1}^{2}\right)+(1-\gamma T)\left(1-w_{1}\right) w_{2}\right] \\
& \frac{\partial R_{2}}{\partial t_{1}}=(1-2 \gamma T)\left(w_{2}-0.5 w_{2}^{2}\right)-(1-\gamma T)\left(1-w_{2}\right) w_{1} \\
& \frac{\partial R_{1}}{\partial t_{2}}=\sigma\left[(1-2 \gamma T)\left(w_{1}-0.5 w_{1}^{2}\right)-(1-\gamma T)\left(1-w_{1}\right) w_{2}\right] \\
& \frac{\partial R_{2}}{\partial t_{2}}=(1-2 \gamma T)\left(w_{2}-0.5 w_{2}^{2}\right)+(1-\gamma T)\left(1-w_{2}\right) w_{1}
\end{aligned}
$$

As before, a measure of competitive inequality is obtained using $M R_{1}-M R_{2}=0$ :

$$
M R_{1}-M R_{2}=0 \Rightarrow \frac{w_{1}^{2}}{w_{2}^{2}}=\sigma+\alpha\left(\frac{1-2 \gamma T}{1-\gamma T}\right)\left(\frac{\sigma\left(w_{1}-0.5 w_{1}^{2}\right)-\left(w_{2}-0.5 w_{2}^{2}\right)}{w_{2}^{2}}\right)
$$

We note $(1-2 \gamma T) /(1-\gamma T)>0$, and $\sigma\left(w_{1}-0.5 w_{1}^{2}\right)-\left(w_{2}-0.5 w_{2}^{2}\right)>0$. Competitive inequality is lower with equal revenue sharing ( $\alpha=0$ ) than it is with no revenue sharing $(\alpha=1)$. As $\alpha$ decreases within the range 0 $<\alpha<1$, competitive inequality decreases. For $\alpha=0$, the joint profit-maximizing solution for $\left\{t_{1}, t_{2}\right\}$ is obtained as follows:

$$
M R_{1}+M R_{2}=2 c \Rightarrow(1-2 \gamma T)\left\{\sigma\left(w_{1}-0.5 w_{1}^{2}\right)+\left(w_{2}-0.5 w_{2}^{2}\right)\right\}=4 c
$$

The left-hand-side of [4] is positive, and a non-degenerate solution exists.

It is also of interest to obtain solutions under an alternative team owners' objective function of win-percent maximization, subject to a zero profit constraint. The conditions are

$$
\begin{aligned}
& A R_{1}=\alpha \frac{R_{1}}{t_{1}}+\frac{(1-\alpha)}{2}\left\{\frac{R_{1}+R_{2}}{t_{1}}\right\}=c \\
& A R_{2}=\alpha \frac{R_{2}}{t_{2}}+\frac{(1-\alpha)}{2}\left\{\frac{R_{1}+R_{2}}{t_{2}}\right\}=c
\end{aligned}
$$


where $A R_{i}$ denotes average (net) revenue. A measure of competitive inequality is obtained as follows:

$$
A R_{1}-A R_{2}=0 \Rightarrow \frac{w_{1}}{w_{2}}=\frac{(1+\alpha) \sigma\left(w_{1}-0.5 w_{1}^{2}\right)+(1-\alpha)\left(w_{2}-0.5 w_{2}^{2}\right)}{(1-\alpha) \sigma\left(w_{1}-0.5 w_{1}^{2}\right)+(1+\alpha)\left(w_{2}-0.5 w_{2}^{2}\right)}
$$

For $\alpha=1$ (no revenue sharing), $w_{1} / w_{2}=\sigma\left(w_{1}-0.5 w_{1}^{2}\right) /\left(w_{2}-0.5 w_{2}^{2}\right)$. For $\alpha=0$ (equal revenue sharing) $w_{1} / w_{2}=1$. Note that $\sigma\left(w_{1}-0.5 w_{1}^{2}\right) /\left(w_{2}-0.5 w_{2}^{2}\right)>1$. As in the case of profit maximization, competitive inequality is lower with equal revenue sharing $(\alpha=0)$ than it is with no revenue sharing $(\alpha=1)$. In the former case, both teams have the same net revenue function, and both take the same decision concerning the quantities of talent they hire. Accordingly $w_{1}=w_{2}$, and there is perfect competitive equality. Using $A R_{1}+A R_{2}=2 c$, it is straightforward to show that the solutions for $\left\{t_{1}, t_{2}\right\}$ are non-degenerate for both of the polar cases, $\alpha=1$ and $\alpha$ $=0$.

In Figure $1, B R_{1}$ and $B R_{2}$ are the best-response functions of teams 1 and 2, used to identify the Nash equilibrium solution to the profit maximization model. Figure 1 tracks the progression from the Nash equilibrium to the non-degenerate joint profit maximization equilibrium in the profit maximization model. Competitive inequality decreases as $\alpha \rightarrow 0$ and the rays from the origin become steeper. Figure 1 also tracks the progression between the counterparts of these two equilibria in the win-percent maximization model.

Even when using the appropriately specified revenue function, the joint profit maximization equilibrium envisages both teams divesting themselves of large proportions of their playing talents. The competitive aspect of the Nash equilibrium encourages the teams to spend more on playing talent for individual profit maximization than they would for joint profit maximization. In the win-percent maximization model, the total expenditure on playing talent is not highly sensitive to $\alpha$, but the distribution of talent between the two teams is highly sensitive. In this case, the analysis suggests that revenue sharing would be effective in reducing competitive inequality without damaging playing standards.

\section{Conclusions}

In this paper, we develop an economic model of a professional sports league in which the teams acquire playing talent in an external market. Several earlier formulations of this open model rely upon an inappropriately specified revenue function. Team revenues should depend upon the absolute quality of the teams, as well as their relative quality measured by win-percent. An inference that has been cited widely in this literature, that the introduction of a gate revenue-sharing arrangement increases competitive inequality in an open model, is flawed. This inference is based on an interpolation between a Nash equilibrium solution for the case of no revenue sharing, and a joint profit maximization solution that is degenerate when revenue is dependent on relative team

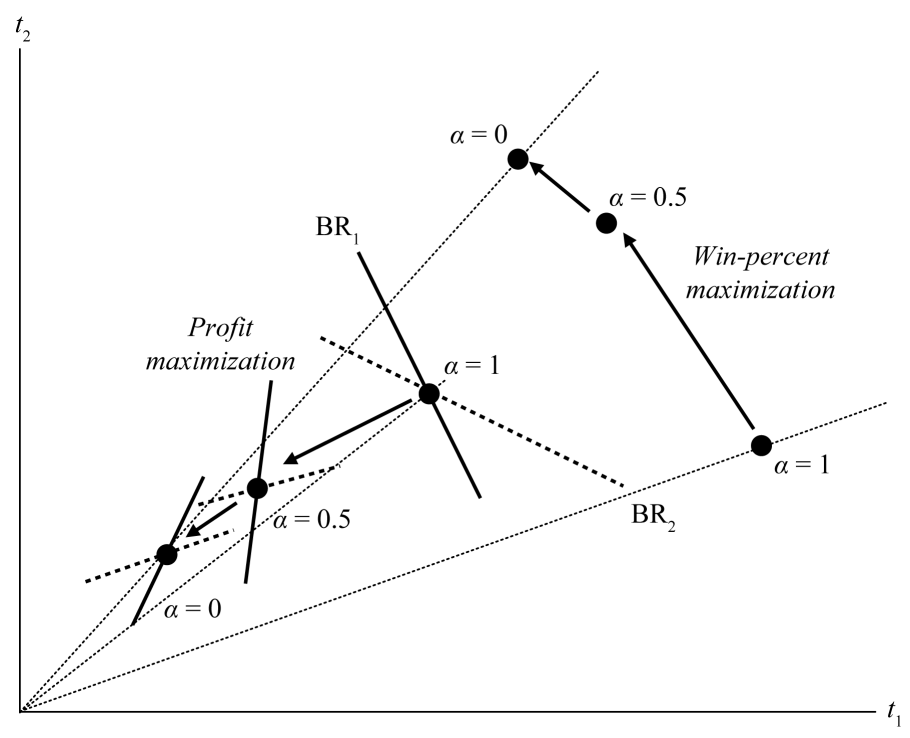

Figure 1. Effects of revenue sharing. 
quality but not on absolute quality.

In an appropriately specified formulation of the open model, revenue sharing reduces competitive inequality. If the team owners' objective is profit maximization, revenue sharing reduces the incentives for team owners to spend heavily on playing talent. This means that a reduction in competitive inequality is achieved at the expense of a significant reduction in playing standards. If the team owners' objective is win-percent maximization, however, revenue sharing is an effective tool for reducing competitive inequality without causing any significant lowering of playing standards.

\section{References}

[1] Vrooman, J. (2009) Theory of the Perfect Game: Competitive Balance in Monopoly Sports Leagues. Review of Industrial Organization, 34, 5-44. http://dx.doi.org/10.1007/s11151-009-9202-7

[2] Fort, R. and Quirk, J. (1995) Cross-Subsidization, Incentives, and Outcomes in Professional Team Sports Leagues. Journal of Economic Literature, 33, 1265-1299.

[3] Dietl, H., Lang, M. and Rathke, A. (2011) The Combined Effect of Salary Restrictions and Revenue Sharing in Sports Leagues. Economic Inquiry, 49, 447-463. http://dx.doi.org/10.1111/j.1465-7295.2010.00330.x

[4] Szymanski, S. and Késenne, S. (2004) Competitive Balance and Gate Revenue Sharing in Team Sports. Journal of Industrial Economics, 52, 165-177. http://dx.doi.org/10.1111/j.0022-1821.2004.00220.x

[5] Késenne, S. (2007) The Peculiar Economics of Professional Football in Europe. Scottish Journal of Political Economy, 54, 388-399. http://dx.doi.org/10.1111/j.1467-9485.2007.00421.x

[6] Cyrenne, P. (2009) Modelling Professional Sports Leagues: An Industrial Organization Approach. Review of Industrial Organization, 34, 193-215. http://dx.doi.org/10.1007/s11151-009-9207-2

[7] Fort, R. and Winfree, J. (2009) Sports Really Are Different: The Contest Success Function, Marginal Product, and Marginal Revenue in Pro Sports Leagues. Review of Industrial Organization, 34, 69-80. http://dx.doi.org/10.1007/s11151-009-9201-8

[8] Feess, E. and Stahler, F. (2009) Revenue Sharing in Professional Sports Leagues. Scottish Journal of Political Economy, 56, 256-266. http://dx.doi.org/10.1111/j.1467-9485.2009.00483.x

[9] Falconieri, S., Palomino, F. and Sakovics, J. (2004) Collective versus Individual Sale of Television Rights in League Sports. Journal of the European Economic Association, 5, 833-862. http://dx.doi.org/10.1162/1542476042782305 